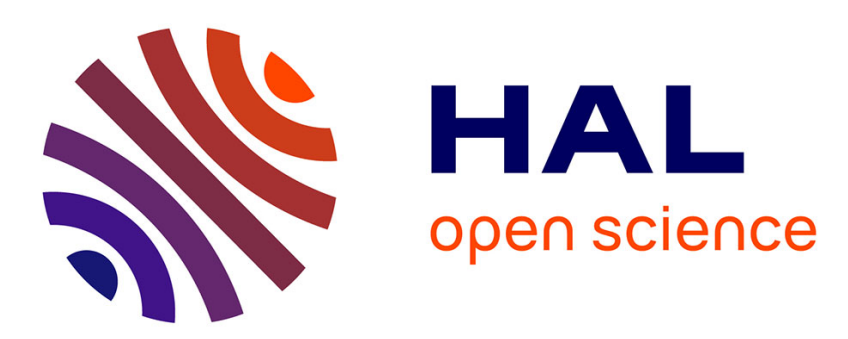

\title{
Aging of Organic Matrix Composite Materials
}

Xavier Colin, Jacques Verdu

\section{To cite this version:}

Xavier Colin, Jacques Verdu. Aging of Organic Matrix Composite Materials. Wiley Encyclopedia of Composites, Wiley, pp.1-16, 2011, 978-0-470-12828-2. 10.1002/9781118097298.weoc005 . hal02623907

\section{HAL Id: hal-02623907 https://hal.science/hal-02623907}

Submitted on 31 Aug 2020

HAL is a multi-disciplinary open access archive for the deposit and dissemination of scientific research documents, whether they are published or not. The documents may come from teaching and research institutions in France or abroad, or from public or private research centers.
L'archive ouverte pluridisciplinaire HAL, est destinée au dépôt et à la diffusion de documents scientifiques de niveau recherche, publiés ou non, émanant des établissements d'enseignement et de recherche français ou étrangers, des laboratoires publics ou privés. 


\section{AGING OF ORGANIC MATRIX COMPOSITE MATERIALS}

\author{
XAVIER COLIN AND \\ JACQUES VERDU \\ ARTS ET METIERS ParisTech, \\ Paris, France
}

\section{INTRODUCTION}

Among the wide variety of organic matrix composite (OMC) applications, very scarce are those for which durability is not a key property. This is the reason why OMC aging raised a relatively abundant literature in the past half century.

Aging can be defined as a slow (e.g., needing the recourse to accelerated aging tests) and irreversible (in use conditions) evolution of the chemical structure, morphology (in its widest sense), and/or composition of the material. It is a technically and economically important problem when evolution leads to a deleterious change of use properties. This problem can be crucial in highly demanding domains, for instance in aerospace applications, which explains why a great part of the research on $\mathrm{OMC}$ aging was induced and supported by the aerospace industry.

Ideally, for an user, lifetime could be defined as follows: in a given structure, used in the given conditions, the lifetime is the age at which the probability of failure reaches an arbitrarily defined value. The main objective of research on material aging is to predict the lifetime. This prediction always involves an extrapolation. Empirical models, which can be efficient in interpolations, are inadequate in extrapolations. The objective of the research is thus to build nonempirical lifetime prediction models that need the knowledge of aging mechanisms. Two categories of aging mechanism can be distinguished.

1. Mechanical aging, in which failure results only from thermomechanical processes (creep, fatigue). This case is often treated with more or less sophisticated thermodynamical tools. Prominent contributors are Refs 1-4. These phenomena, which are relevant to composite mechanics, are not reported here.

2. Physicochemical aging resulting essentially from the interaction of the material with environmental agents such as radiation, oxygen, or water. This article focuses on this category of aging process.

Among the environmental degradation modes, some are set out here. Photochemical aging affects only a very thin superficial layer of a few dozens of micrometers [5] and thus concerns coatings rather than composites. Radiochemical aging can penetrate deeply in composites and modify their mechanical properties. Results on usual thermoset matrices [6] and on industrial composites [7] are available, but the scarceness of the scientific literature and the restricted range of applications led us to sacrifice this topic for the benefit of more important ones. Biochemical aging is also negligible, in common industrial composites, although it could become important if materials issued from the "green chemistry" would replace, in the future, those coming from the organic synthesis. Physical aging resulting from structural relaxation in glassy state leads to an increase in the matrix yield stress and a decrease in its creep compliance and ductility [8]. Many papers have been published on the physical aging of composite matrices, especially epoxies [9], but there is no clear evidence on the practical importance of physical aging in composite durability. As a matter of fact, it must be independent of the atmosphere, whereas degradation is considerably faster in air than in neutral atmosphere, in most cases.

Finally, we focus on two main aging modes, which cover the great majority of industrial aging problems: "humid aging" resulting from the material interaction with water (in liquid or vapor state) and "thermo-oxidative aging" resulting from the material interaction with atmospheric oxygen. Each aging mode is the subject of a section. The first section is devoted to problems common to both aging modes.

\section{GENERAL PROBLEMS IN COMPOSITE AGING}

\section{Interface/Interphase}

Common OMCs can be considered as triphasic materials, as schematized in Fig. 1.

Except in very scarce cases, reinforcing agents, for instance, glass or carbon fibers, are stable in use conditions. OMCs thus perish by their weakest organic component: sometimes matrix, sometimes interface/interphase. The role of the latter is illustrated by the example of short glass fiber-thermoplastic composites exposed to boiling water [10] in Table 1.

The fact that for these three polymers, composite samples degrade more rapidly than the corresponding unfilled samples can be explained only by the occurrence of interfacial degradation. The literature reporting experimental evidences of the interfacial degradation, in humid as well as in thermo-oxidative aging, is relatively abundant, but the transformation of these results into nonempirical kinetic models for lifetime prediction appears extremely difficult for, at least, two reasons:

1. The triphasic model of Fig. 1 is often an oversimplification. Precise investigations reveal a multilayer structure and/or the presence of structural gradients in the interphase [11,12]. How to localize exactly the decisive environmental effects? How to write the corresponding kinetic equations?

2. Even in the ideal case where the interfacial mechanisms are well identified, how to establish quantitative relationships between their conversion and the mechanical properties of practical interest? 


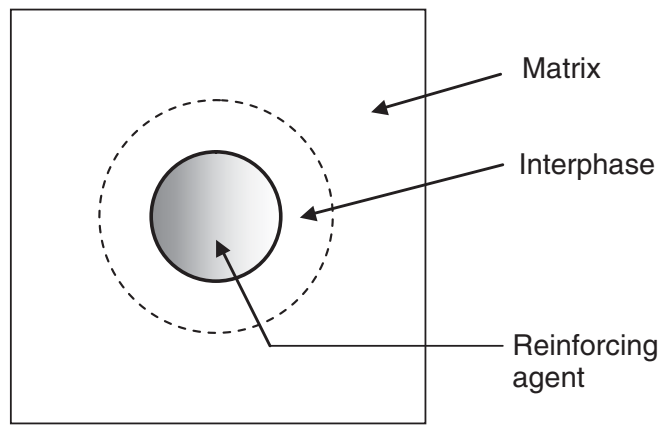

Figure 1. Schematization of the triphasic structure of composites.

Table 1. Strength Retention (Percent of the Initial Value) After Immersion in Boiling Water

\begin{tabular}{|c|c|c|c|}
\hline \multirow[t]{2}{*}{ Polymer } & \multirow[t]{2}{*}{ Glass Fiber (\%) } & \multicolumn{2}{|c|}{ Strength Retention (\%) } \\
\hline & & After 100 & er $1000 \mathrm{~h}$ \\
\hline Polycarbonate (PC) & 30 & 51 & 28 \\
\hline Polycarbonate (PC) & 0 & $100+{ }^{a}$ & 28 \\
\hline $\begin{array}{l}\text { Polyoxymethylene } \\
\text { (POM) }\end{array}$ & 30 & 71 & 57 \\
\hline $\begin{array}{l}\text { Polyoxymethylene } \\
\text { (POM) }\end{array}$ & 0 & $100+^{a}$ & 98 \\
\hline $\begin{array}{l}\text { Modified Polyphenylene } \\
\text { oxide (PPO) }\end{array}$ & 30 & 84 & 65 \\
\hline $\begin{array}{l}\text { Modified Polyphenylene } \\
\text { oxide (PPO) }\end{array}$ & 0 & $100+^{a}$ & 100 \\
\hline
\end{tabular}

Source: Adapted from Ref. 10

${ }^{a}$ Strength increase after exposure.

Here also, the problem remains partially unresolved $[13,14]$ despite the considerable amount of research done in this field in the past 30 years.

From the point of view of nonempirical kinetic modeling for lifetime prediction, interface/interphase degradation remains, in the first decade of the twenty-first century, a widely open research domain.

\section{Transport Processes}

Early theoretical developments on water or oxygen transport in composites were inspired by the analogy between gas diffusion and heat, electricity or magnetism conduction in heterogeneous materials, profiting the work of prestigious pioneers such as Maxwell and Rayleigh [15]. The discipline received a strong impulse in the 1970s when problems of humid aging emerged in aeronautics. It was soon recognized that water transport kinetic modeling could be the key for lifetime prediction and that diffusion anisotropy, linked to the fibers spatial arrangement in laminates, is an important characteristic of fiber composites.

Examples of values of oxygen diffusivity [16] determined on thin composite samples by permeation using the half-time method [17] are reported in Table 2. As expected, oxygen diffusion is largely favored in the longitudinal direction of fibers $(/ /)$ than in the transverse one $(\perp)$.
Table 2. Values of Oxygen Diffusivity for Glass and Carbon Fibers/Epoxy Matrix in the Longitudinal $\left(D_{/ /}\right)$and Transverse Directions $\left(D_{\perp}\right)$ of the Fibers

\begin{tabular}{ccccc}
\hline $\begin{array}{c}\text { Temperature } \\
\left({ }^{\circ} \mathrm{C}\right)\end{array}$ & $\begin{array}{c}D \text { for Glass/ } \\
\text { Epoxy }\left(\mathrm{m}^{2} / \mathrm{s}\right)\end{array}$ & \multicolumn{2}{c}{$\begin{array}{c}D \text { for Carbon/ } \\
\text { Epoxy }\left(\mathrm{m}^{2} / \mathrm{s}^{1}\right)\end{array}$} \\
\cline { 2 - 5 } & $\mathrm{D}_{/ /} \times 10^{-12}$ & $D_{\perp} \times 10^{-12}$ & $\mathrm{D}_{/ /} \times 10^{-12}$ & $D_{\perp} \times 10^{-12}$ \\
\hline 180 & 3.75 & 0.70 & 2.59 & 0.70 \\
200 & 5.36 & 1.10 & 3.70 & 1.10 \\
\hline
\end{tabular}

The epoxy matrix is an anhydride-cross-linked epoxy. The volume fractions of glass and carbon are 64 and $69 \%$, respectively [16].

Simplified homogenized models, based only on geometric considerations, were proposed to evaluate the effective water diffusivities in the different principal directions of unidirectional laminates, knowing the diffusivities in the fiber and the polymer matrix [18]. As an example, in the fiber direction, one can write

$$
D_{/ /}=V_{\mathrm{f}} D_{\mathrm{f}}+\left(1-V_{\mathrm{f}}\right) D_{\mathrm{m}}
$$

where $D_{\mathrm{f}}, D_{\mathrm{m}}$, and $\mathrm{D}_{/ /}$are the respective diffusion coefficients in the fiber, the polymer matrix, and the laminate and $V_{\mathrm{f}}$ is the volume fraction of fibers in the laminate.

These models make full account of the fact that water diffusivity is privileged in the fiber direction than in the transverse one [19]:

$$
D_{/ /}=\frac{1-V_{\mathrm{f}}}{1-2 \sqrt{\frac{V_{\mathrm{f}}}{\pi}}} D_{\perp},
$$

where $D_{/ /}$and $D_{\perp}$ are the respective diffusion coefficients in the longitudinal and transverse directions of the fibers.

Colin et al. [20] showed that such models can also be used to predict oxygen diffusivity in composites. More recently, Roy and Singh [21] showed that these models can be improved to take into account physical discontinuities such as highly permeable fiber-matrix interface or fiber-matrix debonding due to oxidative shrinkage and erosion.

\section{Mechanodiffusive Coupling}

Even when no external loads are applied during aging, a stress state develops in OMCs as a result of diffusion-induced gradients of the volumetric properties, for example, swelling in humid aging and shrinkage in oxidative aging (see corresponding sections). Stresses are expected to influence gas or vapor diffusion. The simplest approach to the problem is to start from free volume considerations. Tensile stresses create free volume:

$$
f_{\mathrm{S}}=\frac{\mathrm{d} V}{V}=\varepsilon(1-2 v),
$$

where $f_{\mathrm{S}}$ is the free volume fraction linked to the elastic strain $\varepsilon . v$ is the Poisson ratio.

Conversely, compression decreases free volume. It remains to relate the free volume fraction to the gas or vapor diffusion coefficient. Despite the fact that the free 
volume theory is essentially applicable to the rubbery state [22], there are extensions to the glassy state [23], but this approach seems questionable to us, at least, in the case of water [24]. A more general approach based on thermodynamics has been recently proposed. The key quantity, here, is the chemical potential that depends on temperature and stress state. This would influence gas solubility [25] as well as diffusion [26]. According to these authors, the local gas concentration $[R]$ would be given by the following equation:

$$
\frac{\mathrm{d}[R]}{\mathrm{d} t}=D_{\mathrm{R}} \operatorname{div}(\operatorname{grad}[R])+\beta_{\mathrm{R}} \operatorname{div}(\operatorname{grad}(\operatorname{tr} \varepsilon)),
$$

where $D_{\mathrm{R}}$ is the coefficient of diffusion, $\varepsilon$ is the deformation tensor, and $\beta_{\mathrm{R}}$ is a coupling parameter to be determined experimentally.

Coupling parameters are difficult to determine in practical cases because (i) diffusion measurements under stress are not easy and (ii) coupling parameters are generally low and stress levels cannot be very high, otherwise creep and damages complicate the interpretation of results. When the gas reacts with the polymer (hydrolysis and oxidation), there is a way to determine $\beta_{\mathrm{R}}$ from the thickness degradation profiles (see below).

\section{Reaction-Diffusion Coupling}

Let us consider a polymer sample of thickness $L$ that is small relative to its other dimensions and a molecular reagent $Y$ (water or oxygen) coming from the environment and diffusing through the polymer according to Fick's law, with a diffusion coefficient $D$. To simplify, one will consider the case where $Y$ is consumed by its reaction with the polymer according to a first-order process:

$$
\frac{\mathrm{d}[Y]}{\mathrm{d} t}=-K[Y]
$$

One can define a characteristic time $t_{\mathrm{D}}$ for diffusion and $t_{\mathrm{R}}$ for reaction:

$$
t_{\mathrm{D}}=\frac{L^{2}}{D} \text { and } \quad t_{\mathrm{R}}=\frac{1}{K} .
$$

The physical meaning of these quantities is very simple: at times when one order of magnitude lower than the characteristic time, the phenomenon's progression is negligible, and at times when one order of magnitude higher than the characteristic time, the phenomenon is almost totally achieved. Thus, here, if $t_{\mathrm{D}} \ll t_{\mathrm{R}}$, it means that diffusion is fast enough to continuously saturate the whole sample volume. The reaction will occur homogeneously at its maximum rate (Fig. 2a). If $t_{\mathrm{D}} \gg t_{\mathrm{R}}$, it means that reaction occurs at an appreciable conversion before sorption equilibrium is reached. $Y$ is consumed in the superficial layers of the sample and cannot reach the inner layers (Fig. 2b).

An example of oxidized layer in a carbon fiber/epoxy matrix unidirectional composite is reported in Fig. 3. The thickness of the oxidized layer is more in the longitudinal direction of fibers (Fig. 3b) than in the transverse one
(Fig. 3a) as a result of anisotropy of oxygen diffusion (Eq. 2).

One can define critical conditions from the equality of both above characteristic times that lead to define a critical thickness $L_{\mathrm{C}}$ under the given exposure conditions:

$$
L_{\mathrm{C}}=2\left(\frac{D}{K}\right)^{1 / 2}
$$

The factor 2 comes from the fact that in the majority of cases, the sample is hydrated or oxygenated by both faces. The thickness of the oxidized layer can be defined as:

$$
\ell=\left(\frac{D}{K}\right)^{1 / 2}=\frac{L_{\mathrm{C}}}{2}
$$

This very simple scaling law, which can be derived from a more general approach [28], displays very good heuristic qualities. It allows to predict accurately the order of magnitude of the thickness of the oxidized layer, the sense of its variation with temperature, oxygen pressure, polymer morphology, and so on. A first step toward generalization is to write the balance equation in the case of unidirectional diffusion and reaction in steady state:

$$
\frac{\partial C}{\partial t}=D \frac{\partial^{2} C}{\partial z^{2}}-r(C)
$$

where $r(C)$ is the reagent consumption rate.

Making the assumption of steady state $(\delta C / \delta t=0)$, one obtains a second-order differential equation of which the resolution gives the concentration profile $C=f(z)$, from which it is possible to determine the consumption rate profile $r(C)=r[f(z)]$ and the profile of the number of reagent moles consumed: $Q=r \times t=r[f(z)] \times t$. In the case of hydrolysis, it is generally licit to use first-order kinetics:

$$
r(C)=K C .
$$

In the simplest case of oxidation, an hyperbolic equation can be used in a first approximation:

$$
r(C)=\frac{\alpha C}{1+\beta C} .
$$

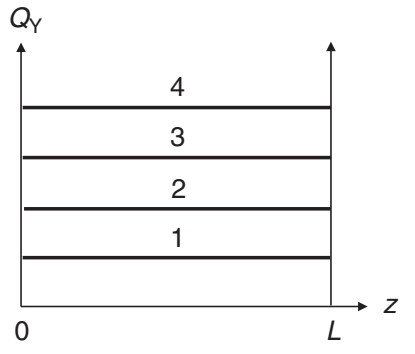

(a)

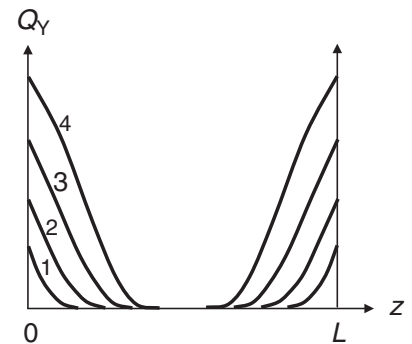

(b)
Figure 2. Schematic shape of reaction product thickness profile in the absence of kinetic control by diffusion (a) and in the case of diffusion-controlled reaction (b). The numbers on the figures indicate increasing exposure times. 


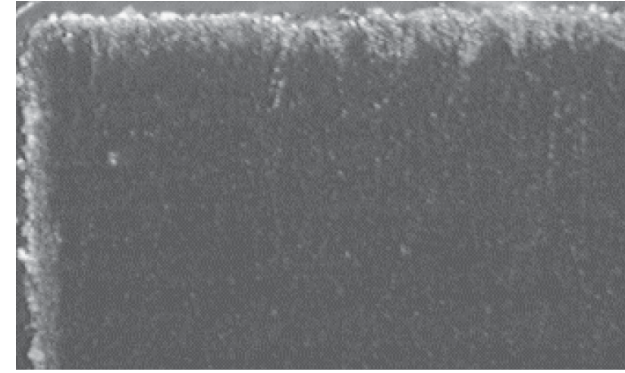

(a)

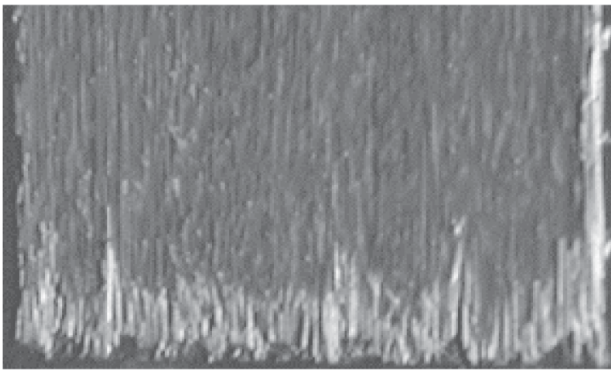

(b)

Figure 3. Oxidized layer in a carbon fibers/epoxy matrix composite having 65 vol\% of fibers (a) parallel and (b) perpendicular to the free surface after $200 \mathrm{~h}$ of exposure to air at $200^{\circ} \mathrm{C}$ [27]. Examination of polished cross sections by optical microscopy using an interferential contrast. The epoxy matrix results from the reaction of a mixture of triglycidyl derivative of $p$-aminophenol (TGAP) and diglycidyl ether of bisphenol F (DGEBF) by diaminodiphenylsulfone (DDS) and is filled by about $30 \mathrm{wt} \%$ of thermoplastic polysulfone (PES).

It reduces to first order $r(C)=C$ at low concentration values, $C \ll 1 / \beta$, and to zero order $r(C)=\alpha / \beta$ at high concentration values, $C \gg 1 / \beta$.

In certain cases of hydrolysis (equilibrated hydrolysis), and in most cases of oxidation, the assumption of steady state is not valid, the reaction rate $[r(C)]$ is a function of time, and the reagent reaction with the polymer is one elementary reaction among many others. In these cases, a new step toward generalization is to incorporate the diffusion term $\left[D \times\left(\delta^{2} C / \delta z^{2}\right)\right]$ in the whole kinetic scheme and to solve the latter in time $(t)$ and space $(z)$ using finite difference or finite element methods. This approach was used for the first time at Arts et Metiers ParisTech (e.g., [29]). The last step toward generalization is to take into account the coupling phenomena, for instance, mechanodiffusive ones [30]:

$$
\frac{\mathrm{d} C}{\mathrm{~d} t}=-r(C)+D \operatorname{div}(\operatorname{grad}(C))+\beta \operatorname{div}(\operatorname{grad}(\operatorname{tr} \varepsilon)),
$$

where $r(C)$ is the rate of reagent consumption derived from the chemical kinetic scheme.

\section{HUMID AGING}

\section{Introduction}

The term humid aging covers all the aspects of aging due to the interaction of water with the material. When the weakest element of the $\mathrm{OMC}$ is the matrix, it is relatively easy to distinguish between physical and chemical humid aging processes. This distinction is not so easy to make in the case where the weakest element is the fiber-matrix interfacial region. As quoted in the section titled "Interface/Interphase," relatively little is known on mechanisms and kinetics of humid aging at interfaces. This is the reason why most of this section is focused on aging processes linked to matrix interaction with water.

Physical water-matrix interactions fall under the category of aging (e.g., irreversible) processes when they are at the origin of the following causal chain:

$$
\begin{array}{r}
\text { water sorption/desorption } \rightarrow \text { swelling/deswelling } \rightarrow \\
\text { stress state } \rightarrow \text { damage }
\end{array}
$$

Here, aging appears reversible at the molecular scale (no change of chemical structure) but irreversible at the macroscopic scale.

In the case of water-matrix chemical (e.g., never totally reversible) interaction, one would rather have the following causal chain:

$$
\begin{array}{r}
\text { water absorption } \rightarrow \text { hydrolysis } \rightarrow \text { chain scission } \rightarrow \\
\text { embrittlement }
\end{array}
$$

or $\quad$ water absorption $\rightarrow$ hydrolysis $\rightarrow$ chain scission $\rightarrow$ osmotic cracking

"Pure" physical aging can occur when the polymer is nonreactive with water, for instance, in most cases of amine-cross-linked epoxies. In contrast, pure chemical aging cannot exist because to react, water must penetrate the material, inducing thus physical aging, although this can be negligible.

An example of combining chemical and physical effects of water absorption on a glass fiber/polymer composite is shown in Fig. 4. The strength decrease in dry state is irreversible and due to matrix hydrolysis. The strength decrease in wet state is mainly due to matrix plasticization by water. Plasticization effects are reversible.

\section{Physical Processes of Humid Aging}

The most common way to study physical interactions between water and a material is to make sorptiondesorption tests in air, at controlled temperature, and at a relative hygrometry $(\mathrm{RH})$. A typical curve is presented in Fig. 5. Two time domains can be clearly distinguished:

1. The transient, during which the quantity of absorbed water increases continuously. During this period, the water concentration is inhomogeneously distributed in the sample thickness. 


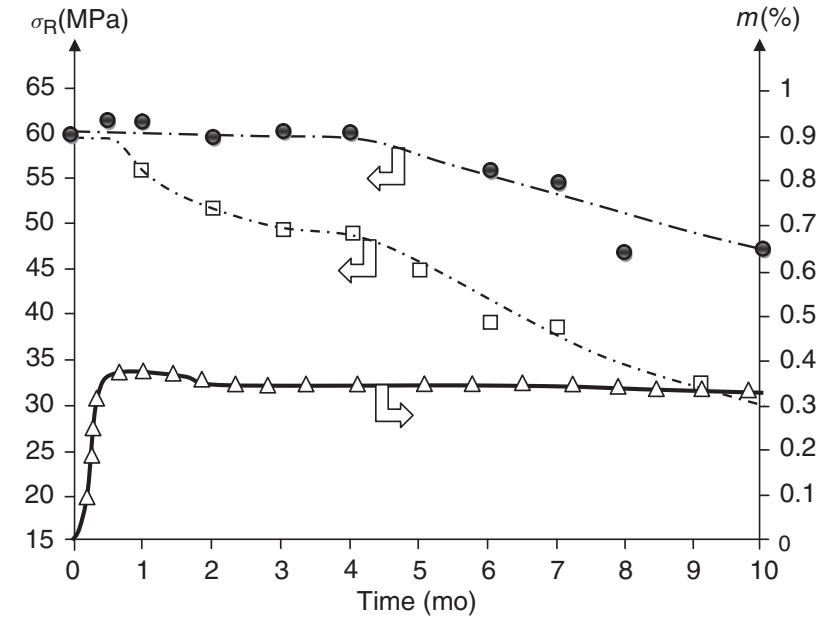

Figure 4. Hydrolytic aging of an E-glass fibers/polyester laminate after immersion in water at $60^{\circ} \mathrm{C}$. The polyester is a fumarate/isophthalate of propylene glycol cross-linked by $45 \mathrm{wt} \%$ styrene. The weight fraction of glass is $50 \%$. $\square$, shear strength in wet state; $\bullet$, shear strength in dry state; and $\Delta$, mass uptake linked to water absorption. Source: Adapted from Ref. 31.
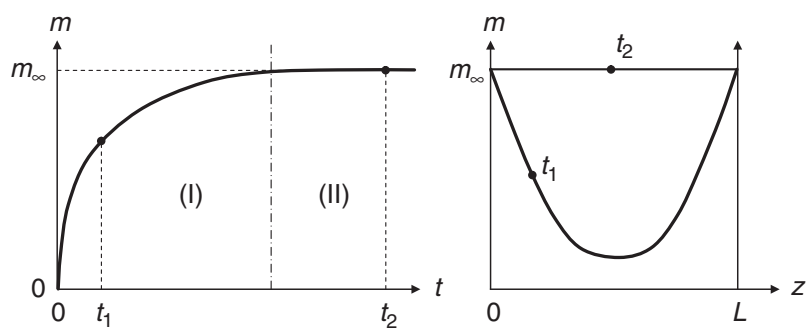

(a)

(b)

Figure 5. (a) Typical shape of a sorption curve. (b) Concentration thickness profile at two different times of exposure. $m$, mass uptake; and $m_{\infty}$, equilibrium mass uptake.

2. The equilibrium, in which the water concentration reaches its maximum value (in the chosen exposure conditions) in all the points of the sample volume. It is thus homogeneously distributed in an initially homogeneous matrix.

Equilibrium Properties. The equilibrium water mass uptake $m_{\infty}$, mass fraction $\mu_{\infty}$, concentration in the matrix $C_{\infty}$, and concentration in the composite $C_{\infty}^{\prime}$ are linked by the following relationships:

$\mu_{\infty}=\frac{m_{\infty}}{1+m_{\infty}}, C_{\infty}=\frac{\mu_{\infty}}{18}(\mathrm{~mol} / \mathrm{g})$, and $\quad C_{\infty}^{\prime}=C_{\infty}(1-f)$,

$f$ being the fiber mass fraction in the composite.

Small deviations from this equation can be observed, especially in the case of interface porosity and interphase contribution to hydrophilicity. In most cases of industrial interest, $m_{\infty} \ll 0.1$, so that in a first approximation, $\mu_{\infty}$, $C_{\infty}$, and $C_{\infty}^{\prime}$ are proportional to $m_{\infty}$.
Effect of Relative Hygrometry (RH). Since water is far below its critical point $\left(T_{\mathrm{CR}}=647 \mathrm{~K}\right)$, the pertinent environmental parameter is the water activity $a$.

For humid atmospheres, with water partial pressure $p$ :

$$
a=\frac{p}{p_{\mathrm{S} 0}}=\frac{\mathrm{RH}}{100},
$$

$p_{\mathrm{S} 0}$ being the saturated vapor pressure of water.

And in aqueous solutions:

$$
a=\frac{p_{\mathrm{S}}}{p_{\mathrm{S} 0}}
$$

where $p_{\mathrm{S}}$ is the saturated vapor pressure above the solution.

In other words, exposure to a water solution is equivalent to exposure to a humid atmosphere of the same activity. The curve $C_{\infty}=f(a)$ is called sorption isotherm. In most cases, sorption isotherms can display three different types of shapes (Fig. 6).

Type A is linear in the whole activity range and corresponds to the case where sorption obeys Henry's law:

$$
C=H a,
$$

where $H$ depends only on temperature.

In Fig. 6, polyamide 11 (PA11), polycarbonate (PC), and poly(bisphenol A sulfone) (PSU) isotherms are of type A.

Type B is also linear at low activities but displays a positive concavity at high activities. This type of isotherm can generally be represented by the sum of two terms:

$$
C=H a+b a^{\mathrm{m}}
$$

The existence of this positive curvature can be attributed to cluster formation, and the above equation can be mathematically derived to determine cluster characteristics using the Zimm-Lundberg theory [34].

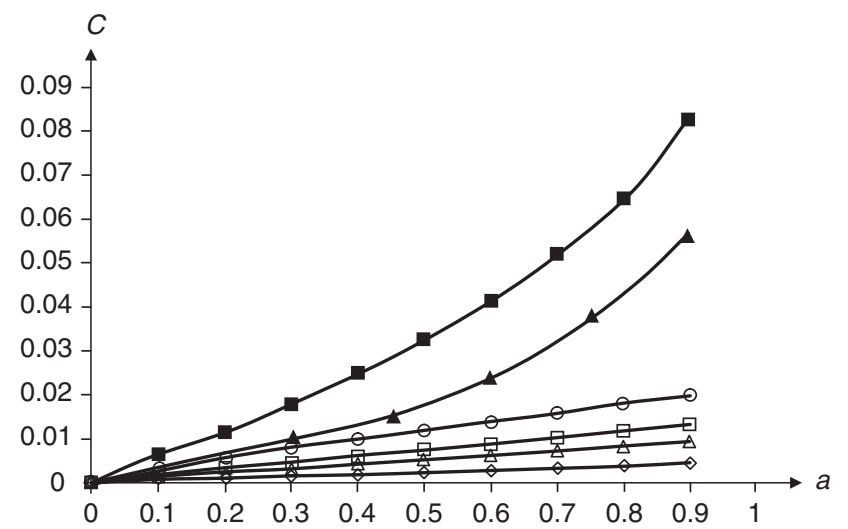

Figure 6. Sorption isotherms at $50^{\circ} \mathrm{C}$ of several polymers: polyamide 6 (PA6); $\mathbf{\Delta}$, alcohol-terminated poly(ethylene adipate) (PADEG); O, polyethersulfone (PES); $\square$, polyamide 11 (PA11); $\Delta$, poly(bisphenol A sulfone) (PSU); and $\diamond$, poly(bisphenol A carbonate) (PC). Source: experimental data from Ref. 32 except for PADEG [33]. 
In Fig. 6, alcohol-terminated poly(ethylene adipate) (PADEG) isotherm is of type B.

Type $\mathrm{C}$ corresponds to type $\mathrm{B}$ to which has been added a negative curvature at low activities. It can be represented by the following equation:

$$
C=\frac{\alpha C_{\mathrm{H}} a}{1+\beta a}+H a+b a^{\mathrm{m}} .
$$

The first term is generally attributed to Langmuir's sorption mechanism. In Fig. 6, polyamide 6 PA6 isotherm is of type C.

Despite an impressive amount of research work since the $1950 \mathrm{~s}$, with, for instance, extensive reviews in the 1960s [35], there is no theory, to our knowledge, to predict the type of sorption isotherm from the polymer structure. Molecular dynamics simulations are used more and more to study polymer-water interactions. In a recent paper, Marque et al. [36] quoted more than 40 articles on this subject. One can hope that such methods will give a new impulse in this research field, but we still are, apparently, far from the above type of prediction.

Effect of Temperature. It can be observed that the equilibrium water concentration in saturated vapor $\left(C_{\mathrm{S}}=C_{\infty}\right.$ at $a=1$ ) depends only slightly on temperature, at least in moderately polar polymers. Detailed investigations show, however, that $C_{\mathrm{S}}$ tends to increase with temperature for polymers of relatively low polarity, for instance, polyesters, and tends to decrease with temperature for polymers of relatively high polarity, for instance, hydroxyl-rich epoxies. An explanation, valid for Henry's regime, but which can be extended to other sorption modes, at least in a first approximation, was proposed by Merdas et al. [37]. According to Henry's law:

$$
C_{\mathrm{S}}=S p_{\mathrm{S}}
$$

where $S$ is the solubility coefficient.

The temperature variation of $S$ and $p_{\mathrm{S}}$ can be represented, at least in a first approach, by the Arrhenius law:

$$
S=S_{0} \exp -\frac{H_{\mathrm{S}}}{R T} \text { and } \quad p_{\mathrm{S}}=p_{\mathrm{S} 0} \exp -\frac{H_{\mathrm{W}}}{R T}
$$

where $H_{\mathrm{W}} \approx 43 \mathrm{~kJ} / \mathrm{mol}$.

So that

$$
C_{\mathrm{S}}=C_{\mathrm{S} 0} \exp -\frac{H_{\mathrm{C}}}{R T}
$$

with

$$
C_{\mathrm{S} 0}=S_{0} p_{\mathrm{S} 0} \text { and } \quad H_{\mathrm{C}}=H_{\mathrm{S}}+H_{\mathrm{W}}
$$

In fact, water-polymer interactions (through hydrogen bonds) are highly exothermic, so that $H_{\mathrm{S}}$ is negative and its absolute value is close to $H_{\mathrm{W}}$. In polymers of relatively low polarity, $\left|H_{\mathrm{S}}\right|<H_{\mathrm{W}}$ and $H_{\mathrm{C}}>0$, so the equilibrium water concentration is an increasing function of temperature. In polymers of relatively high polarity, $\left|H_{\mathrm{S}}\right|>H_{\mathrm{W}}$ and $H_{\mathrm{C}}<0$, so $C_{\mathrm{S}}$ is a decreasing function of temperature.
Effect of Structure. Many authors, for instance, [38], have tried to relate hydrophilicity to the available free volume, but such theories fail to explain why free-volume-rich substances, for instance, liquid hydrocarbons of silicone rubbers, are hydrophobic. It seems clear that hydrophilicity is essentially linked to molecular interactions between water molecules and polar groups in the polymer. In a first approach, it has been tried to assume that water equilibrium concentration is a molar additive function [39], for example, that each chemical group is characterized by a molar contribution independent of its structural neighboring. Schematically, one could define three categories of groups.

1. Groups having a negligible contribution to hydrophilicity: $H_{\mathrm{A}} \approx 0$ mole water per mole of group; for instance,

$$
-\mathrm{CH}_{2}-, \longrightarrow,-\mathrm{CF}_{2}-,-\mathrm{Si}\left(\mathrm{CH}_{3}\right)_{2}-\text {. }
$$

2. Moderately polar groups having a relatively low contribution to hydrophilicity: $H_{\mathrm{B}} \approx 0.1-0.3$ moles water per mole of group; for instance,

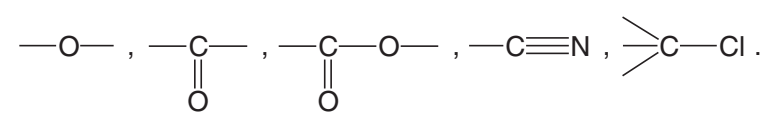

3. Highly polar groups, which are generally able to participate in strong hydrogen bonds: $H_{\mathrm{C}} \approx 1-2$ moles water per mole of group; for instance,<smiles>CNC(C)=O</smiles>

Polymers containing only groups of type A, for instance, polyolefins, fluorinated polymers, silicones, polystyrene, and poly(phenylene sulfide), absorb generally $<0.5 \mathrm{wt} \%$ of water. Polymers containing only groups of types A and B absorb generally $<3 \mathrm{wt} \%$ of water, for instance, linear and cross-linked polyesters, polycarbonate, poly(etheretherketone), polyoxymethylene, and poly(methyl methacrylate). Polymers containing groups of type $\mathrm{C}$ can be water soluble if these groups are of high concentration, for instance, poly(vinyl alcohol) and poly(acrylic acid). They can absorb up to $7 \%$ water in industrial composite matrices such as amine-cross-linked tetraglycidyl methylene dianiline (TGMDA) or triglycidyl derivative of $p$-aminophenol (TGAP) types and polyamides.

Predictions of $C_{\mathrm{S}}$ from the molar additive approach can work in certain homogeneous polymer families [40] provided that "elementary" groups are sufficiently large to take into account eventual intramolecular interactions, for instance, intrasegmental hydrogen bonds. Anyhow, these theories fail to predict hydrophilicities in large families where the polar groups' concentrations vary extensively. It has been found that the molar contribution of these groups, 
for instance, hydroxyls in epoxies or sulfones in polysulfones, decreases and tends to vanish when the group concentration decreases [24,41]. Gaudichet-Maurin et al. [41] proposed a theory according to which an hydrophilic site is not a single group but a pair of polar groups that must satisfy certain geometric requirements to establish a double hydrogen bond with a given water molecule. This theory explains why the group molar contribution and the heat of dissolution $H_{\mathrm{S}}$ are increasing functions of the groups' concentration.

Consequences of Water Absorption. Water absorption induces polymer plasticization, for example, glass transition and temperature depletion. This can be estimated using various physical approaches, among which the free volume theory gives generally good results. According to this theory, $T_{\mathrm{g}}$ of the wet polymer is linked to the volume fraction $v$ of water by the following relationship [42]:

$$
\frac{T_{\mathrm{g}}}{T_{\mathrm{gP}}}=\frac{(1-v) \alpha_{\mathrm{P}} T_{\mathrm{gP}}+v \alpha_{\mathrm{W}} T_{\mathrm{gW}}}{(1-v) \alpha_{\mathrm{P}}+v \alpha_{\mathrm{W}}},
$$

where $T_{\mathrm{gP}}$ and $T_{\mathrm{gW}}$ are the respective glass transition temperatures of the polymer in dry state and water $\left(T_{\mathrm{gW}} \approx\right.$ $130 \mathrm{~K}) . \alpha_{\mathrm{P}}$ and $\alpha_{\mathrm{W}}$ are the respective dilatation coefficients of free volume defined as:

$$
\alpha=\alpha_{1}-\alpha_{\mathrm{g}},
$$

where $\alpha_{1}$ and $\alpha_{\mathrm{g}}$ are the respective dilatation coefficients in liquid (or rubbery) and glassy states.

A simplified version of this theory gives:

$$
\frac{1}{T_{\mathrm{g}}}=\frac{1}{T_{\mathrm{gP}}}+A v,
$$

where

$$
A=\frac{1}{T_{\mathrm{gW}}}-\frac{1}{T_{\mathrm{gP}}}
$$

One sees that the $T_{\mathrm{g}}$ depletion is an increasing function of the water concentration and of $T_{\mathrm{gP}}$. A, which can be considered as a parameter of plasticization efficiency, ranges from about $5 \times 10^{-3} / \mathrm{K}$ for $T_{\mathrm{gP}}=100^{\circ} \mathrm{C}$ to $6 \times 10^{-3} / \mathrm{K}$ for $T_{\mathrm{gP}}=327^{\circ} \mathrm{C}$. Thus the $T_{\mathrm{g}}$ depletion ranges between 7 and $20 \mathrm{~K}$ per percent water absorbed, which corresponds well to the experimental data.

Water absorption also induces polymer swelling. A swelling ratio $\lambda$ can be defined as follows:

$$
\lambda=\frac{v-v_{\mathrm{P}}}{v_{\mathrm{P}}} \times 100 \%,
$$

where $v=1 / \rho$ and $v_{\mathrm{P}}=1 / \rho_{\mathrm{P}}$ are the respective specific volumes of the polymer in wet and dry states. In polymer matrices, $\lambda$ is generally positive but lower than the relative mass uptake $m$. An example given by Belan et al. [43] is shown in Table 3.

Similar observations made, for instance, on polysulfones [44] show that the trends illustrated by Table 3 are general. According to this author, the polymer would swell in order to keep a constant packing density $\rho^{*}$ defined by $\rho^{*}=$ van der Waals volume/total volume.

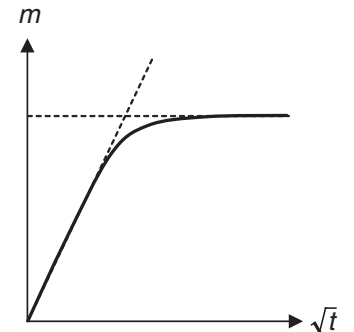

(a)

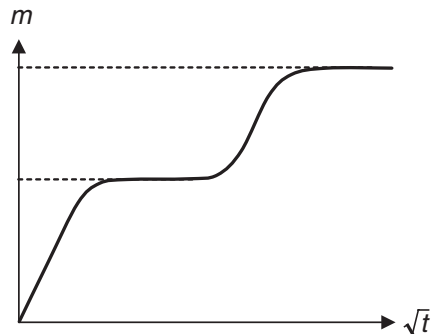

(b)
Figure 7. Shape of sorption curves in the case of (a) Fick's and (b) Langmuir's diffusion processes

Diffusion. Water diffusion in matrices obeys Fick's law in most cases, but it can sometimes display more complex behaviors, often more or less abusively ranged in the category of Langmuir's processes (Fig. 7).

In both cases, the curves $m=f\left(t^{1 / 2}\right)$ are linear in their initial part. In Langmuir's process, diffusion coexists with a "trapping-detrapping" process at peculiar sites able to establish strong interactions with water molecules. The kinetic model of [45] is commonly used in these cases. In amine-cross-linked epoxies, for instance, the trapping-detrapping process is simply the reversible epoxide hydrolysis:

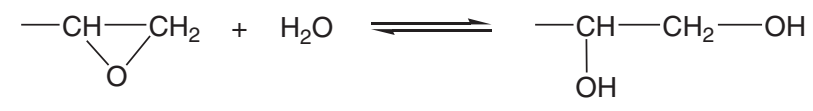

In these networks, the second stage of sorption, characteristic of Langmuir's mechanism, is clearly associated to the presence of unreacted epoxide groups [24].

The relationship between polymer structure and water diffusivity is far from being totally elucidated. Various theories have been proposed [46]. Thominette et al. [47] observed that in various structural series, the diffusivity is a decreasing function of hydrophilicity:

$$
D \approx \frac{B}{m_{\infty}}
$$

where $B \approx(25 \pm 5) \times 10^{-12} \mathrm{~m}^{2} / \mathrm{s}$ for amine-cross-linked epoxies at $100^{\circ} \mathrm{C}, B \approx(18 \pm 4) \times 10^{-12} \mathrm{~m}^{2} / \mathrm{s}$ for aromatic polysulfones at $50^{\circ} \mathrm{C}, B \approx(2.5 \pm 1.0) \times 10^{-12} \mathrm{~m}^{2} / \mathrm{s}$ for styrene-cross-linked polyesters at $50^{\circ} \mathrm{C}$, and $B \approx 2 \times 10^{-12}$ $\mathrm{m}^{2} / \mathrm{s}$ for polyethylenes differing by the concentration of oxygen containing groups at $50^{\circ} \mathrm{C}$. This dependence

Table 3. Equilibrium Water Sorption Characteristics at $30^{\circ} \mathrm{C}$ and $100 \% \mathrm{RH}$ for Styrene-Cross-Linked Polyesters [43]

\begin{tabular}{lcccc}
\hline & \multicolumn{4}{c}{ Sample } \\
\cline { 2 - 5 } & $\mathrm{A}$ & $\mathrm{B}$ & $\mathrm{C}$ & $\mathrm{D}$ \\
\hline$\rho_{\mathrm{P}}\left(\mathrm{kg} / \mathrm{m}^{3}\right)$ & 1200 & 1184 & 1221 & 1153 \\
$m(\%)$ & 1.55 & 1.52 & 5.00 & 2.80 \\
$\lambda(\%)$ & 0.20 & 0.27 & 0.68 & 0.65 \\
$\lambda / m$ & 0.13 & 0.18 & 0.14 & 0.23 \\
\hline
\end{tabular}

$\mathrm{A}$ and $\mathrm{B}$ are based on a maleate-phthalate copolymer. C and D are based on a maleate homopolymer. 


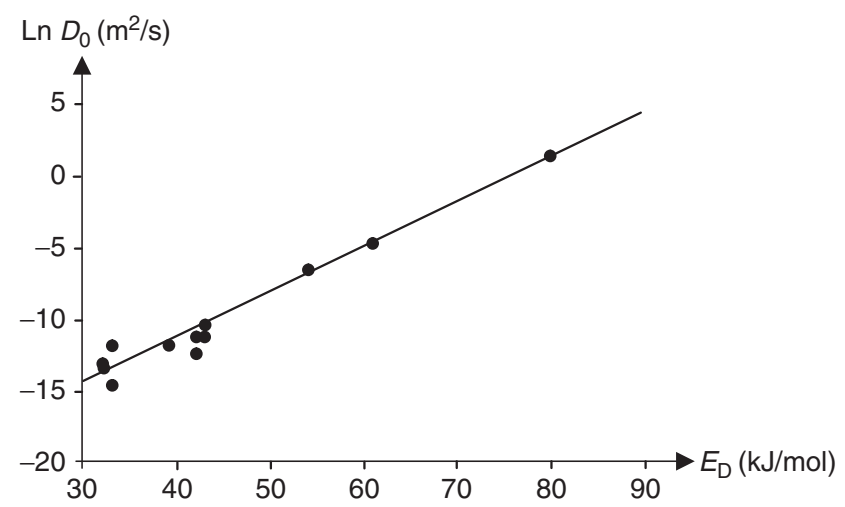

Figure 8. Logarithm of the preexponential coefficient $D_{0}$ against apparent activation energy $E_{\mathrm{D}}$ of water diffusion for several polymers including thermoplastics and thermosets (polyesters and epoxies).

shows that the diffusion rate is slowed down by the water-polymer interactions.

The diffusion coefficient $D$ is generally independent of water activity except in the case of high hydrophilicities where plasticization or clustering effects are important. It increases with temperature:

$$
D=D_{0} \exp -\frac{E_{\mathrm{D}}}{R T}
$$

Typical values of apparent activation energy $E_{\mathrm{D}}$ are $30-40 \mathrm{~kJ} / \mathrm{mol}$ for moderately polar thermoplastics and polyester networks, $30-75 \mathrm{~kJ} / \mathrm{mol}$ for epoxy networks, and $20-40 \mathrm{~kJ} / \mathrm{mol}$ for polyimides. The Arrhenius parameters $D_{0}$ and $E_{\mathrm{D}}$ obey a compensation law (Fig. 8).

The slope of the compensation straightline (0.30) is not very different from the one reported by van Krevelen [39] for permanent gases $(0.276)$. In contrast, the preexponential coefficient ( $\operatorname{Ln} D_{0}=-23.5$ ) is noticeably different ( $\mathrm{Ln}$ $D_{0}=-11.5$ for permanent gases).

Swelling Stresses. From the knowledge of the diffusion law, established from sorption measurements, it is possible to measure the local water concentration in every point at every time, $C=f(x, t)$. In principle, volumetric measurements allow to establish the relationship between water concentration and swelling. This relationship can be used to determine the local swelling ratio $\lambda(x, t)$, which can be decomposed into strain components along trirectangular coordinates. If one assumes that swelling does not affect water transport properties (i.e., the water concentration has been fixed by solving the diffusion law), then the resulting local stresses can be deduced by solving a classical thermoelastic problem [48-50].

But, in general, stresses affect water equilibrium concentration and diffusivity, as evidenced, for example, by Weitsman in epoxy matrix composites [49].

\section{Chemical Processes of Humid Aging}

Hydrolysis Kinetic Aspects. Hydrolytic processes are especially important in two main polymer families containing ester or amide groups in the chain. In these cases, each hydrolysis event is a chain scission.

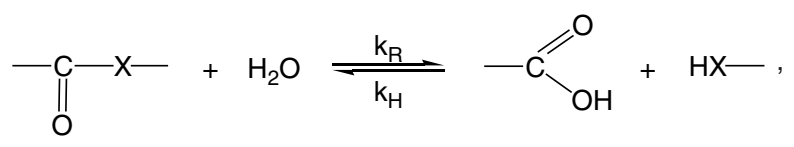

where $\mathrm{X}=-\mathrm{O}-$ (polyesters) or $-\mathrm{NH}-$ (polyamides).

Taking $[-\mathrm{CO}-\mathrm{X}-]=E,[-\mathrm{COOH}]=[\mathrm{HX}-]=b$, and $S=$ number of chain scissions (mole per mass unit), one can write:

$$
\frac{\mathrm{d} S}{\mathrm{~d} t}=k_{\mathrm{H}} C\left(E_{0}-S\right)-k_{\mathrm{R}}\left(b_{0}+S\right)^{2},
$$

where $C$ is the water concentration and $k_{\mathrm{H}}$ and $k_{\mathrm{R}}$ are rate constants depending only on temperature.

Two cases can be distinguished,

1. Equilibrium occurs at high conversions $\left[\left(S_{\infty} / E\right) \approx\right.$ 1]. Since embrittlement occurs at low conversions, far from equilibrium, one can neglect the reverse reaction. Then, the rate of chain scission is well approximated by:

$$
\frac{\mathrm{d} S}{\mathrm{~d} t}=-\frac{\mathrm{d} E}{\mathrm{~d} t}=k_{\mathrm{H}} E_{0} C=K,
$$

$K$ is a pseudo zero-order constant, of which some typical values are given in Table 4.

Polymers containing ester groups (linear or cross-linked polyesters, anhydride-cured epoxies, urethane-cross-linked polyesters, polycarbonate, etc.) belong to this category.

2. Equilibrium occurs at low conversions (typical case of PA11). Then, the reverse reaction cannot be neglected, and the kinetic model is somewhat more complicated [52], especially when acids are present [53]

In composites, interphase hydrolysis can occur, for instance, in the case of certain silane coupling agents [54-56]. The level of knowledge, in this field, remains, however, far from what would be needed to predict the lifetime from mechanical criteria.

Table 4. Approximate Value of the Pseudo Zero-Order Rate Constant of Hydrolysis for Ester-Containing Polymers [51]

\begin{tabular}{lccc}
\hline Polymer & $\begin{array}{c}\text { Temperature } \\
\left({ }^{\circ} \mathrm{C}\right)\end{array}$ & $\begin{array}{c}K \times 10^{8} \\
(\mathrm{~mol} / \mathrm{L} / \mathrm{s})\end{array}$ & $\begin{array}{c}E_{\text {act }} \\
(\mathrm{kJ} / \mathrm{mol})\end{array}$ \\
\hline PET & 99 & 6 & 107 \\
PET & 60 & 0.08 & 107 \\
PC & 85 & 0.2 & 75 \\
PC & 100 & 0.7 & 75 \\
Unsaturated polyesters & 100 & $20-150$ & $70 \pm 10$ \\
Vinyl esters & 100 & $0.2-1.0$ & - \\
\hline
\end{tabular}


Consequences of Hydrolysis. Since hydrolysis is a chain scission process, it always induces embrittlement. In initially ductile linear polymers, such as PET or PA11, the toughness fails of two or three decades when the weight average molar mass reaches a critical value $M_{\mathrm{F}}$ of the order of $10-20 \mathrm{~mol} / \mathrm{kg}$ corresponding to a small multiple of the entanglement molar mass [57]. In the frame of second-order kinetics (rate constant $k_{\mathrm{H}}$ ), it is possible to determine a lifetime value, in fact, the time to embrittlement:

$$
t_{\mathrm{F}}=\left[\frac{2}{E_{0}}\left(\frac{1}{M_{\mathrm{F}}}-\frac{1}{M_{\mathrm{W} 0}}\right)\right]\left(\frac{1}{k_{\mathrm{H}}}\right)\left(\frac{1}{C}\right) .
$$

This nonempirical quantity can be decomposed in three almost independent factors: the first one linked to the polymer structure; the second one to temperature, through Arrhenius law; and the third one to water activity, through sorption isotherm equation.

$N B$ : The third factor can also slightly depend on temperature.

In thermosets, which are often initially brittle, chain scission induces also a decrease in fracture properties, but the structure-property relationships are not well established in this domain

In the most economically important class of hydrolyzable thermosets, for example, unsaturated polyesters (boats, swimming pools, tanks, etc.), failure comes generally from a specific consequence of hydrolysis, osmotic cracking. In laminates, subcutaneous cracks propagate preferentially parallel to the surface, giving blisters. This phenomenon was catastrophic to the composite boat industry in the 1970s-1980s. It was soon understood why cracks propagate. As a matter of fact, they contain water in which solutes, coming from the polyester matrix, create an osmotic pressure that increases until stress concentration at crack tips induces propagation. Then, the pressure decreases until the crack development stops, but new solutes are released by the polymer, the osmotic pressure increases again, and so on $[58,59]$. The mechanism of crack initiation was elucidated by Gautier et al. [60]: it is due to the accumulation of small highly hydrophilic molecules (diacids and dialcohols) resulting from hydrolysis events near the end of dangling chains (which are preexisting or being formed by hydrolysis events on elastically active chains). The composite resistance to osmotic cracking would be thus linked to three factors having additive effects on the initiation rate: the initial presence of solutes linked to the polymerization catalysts, the initial presence of dangling chains (which is a decreasing function of the prepolymer molar mass), and the polyester hydrolysis rate. If, by a proper optimization of the above factors, the rate of small molecules release is lowered enough, then they can eventually disappear (at least partially) by diffusion, and the time to cracking increases considerably or, even, becomes infinite.

In the case of glass fibers/unsaturated polyester matrix composites (boat hulls, swimming pools, tanks etc.), the kinetic curve of weight changes can present the peculiar shape, revealing the presence of an osmotic cracking

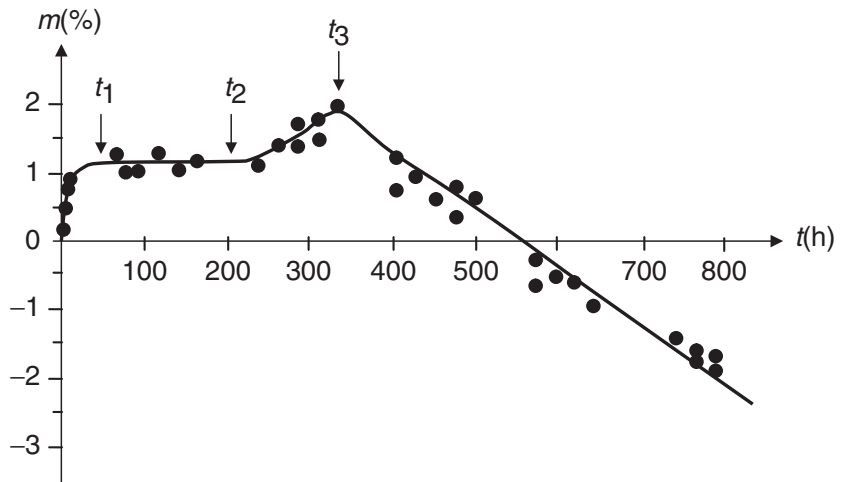

Figure 9. Osmotic cracking in a polyester for boat hulls, as revealed by the kinetic curve of weight changes after immersion in boiling water. The resin is made of maleate/isophthalate (46/54) of propylene glycol cross-linked by $45 \mathrm{wt} \%$ styrene. The samples are sheets of 3-mm thickness. Source: Ref. 61.

(Fig. 9). Such a behavior can be explained as follows: at $t_{1}$, sorption equilibrium is reached; at $t_{2}$, cracks initiate and the sorption capacity of the sample increases; and at $t_{3}$, the cracks coalesce and the organic molecules, resulting from the polymer hydrolysis and dissolved into the water contained in the cracks, disappear in the bath. The weight begins to decrease.

$N B$ : Both phenomena of sorption and cracking are distinguishable because the sample thickness $L$ is low enough to have $t_{\mathrm{D}}<t_{\mathrm{C}}$, where $t_{\mathrm{D}}=L^{2} / D$ is the characteristic time of diffusion, $D$ is the diffusion coefficient of water in the material, and $t_{\mathrm{C}}$ is the characteristic time of osmotic cracking, mainly linked to the hydrolysis rate and thickness independent [60].

\section{THERMO-OXIDATIVE AGING}

\section{A Brief History}

The modern vision of oxidation kinetics was first elaborated by Semenov (received Nobel Prize in 1956), which recognized, for the first time, the branched radical chain character of the oxidation processes in any substrate [62]. Semenov created and animated a very powerful research team at the Institute of Chemical Physics in Moscow. The very well-known names of Emanuel or Denisov, authors of several books and monographs on the subject, belong to this school. Applications of these concepts to polymers emerged essentially after the Second World War.

In the Western countries, the pioneers are British workers [63]. In the United States, Tobolsky and coworkers [64] had a decisive contribution to kinetic modeling. In the $1960 \mathrm{~s}-1970 \mathrm{~s}$, there was a fast development of the discipline in the United States where Ingold, Mayo, Russel, Shelton, Uri, Reich, and Stivala, among the authors, were prominent contributors [65,66]. During the same period, the research remained very active in former USSR [67,68]. Problems of reaction-diffusion coupling emerged in the 1980s [69-71] as mentioned in the section titled "General Problems in Composite Aging." The fact that thermal aging 
of composite materials results from a diffusion-controlled reaction did not become apparently a research objective before the beginning of 1990s [72-74]. Moreover, the results obtained by the polymer (and radical oxidation) community were totally ignored by the composites community until the turn of the century. The history of the past decade is included in the following sections.

\section{The Standard Mechanistic Scheme (SMS)}

Analytical studies of the polymer thermal oxidation can reveal a great diversity of oxidation products (several dozens in certain cases), which is usually indicative of a very complex mechanistic scheme, and thus, to a not less complex kinetic scheme. However, generally, only a small number of elementary chemical events "dictate their rhythm" to the whole process (Table 5).

The main characteristics of thermal oxidation (at moderate temperatures where the substrate would be stable in neutral atmosphere) are the following ones:

1. Propagation involves two elementary steps: addition of oxygen to radicals $\mathrm{P}^{\bullet}$ (II) and hydrogen abstraction to the substrate by $\mathrm{PO}_{2}{ }^{\bullet}$ radicals, which regenerates a radical $\mathrm{P}^{\bullet}$ (III). Generally, $k_{2} / k_{3} \gg 10^{6}$ (Table 5).

2. Initiation results from the decomposition of hydroperoxides. The reaction generates its own initiator, which explains the eventual existence of an induction period in kinetics and the autoaccelerated character of the reaction. Initiation can be unimolecular $(\delta=1$, $\alpha=2, \beta=0$ ) or bimolecular ( $\delta=2, \alpha=1, \beta=1$ ). It can also begin unimolecular and turn to bimolecular when the hydroperoxide concentration reaches a critical value.

Tobolsky et al. [64] elaborated kinetic models that are able to simulate the main features of polymer thermal oxidation. Unfortunately, these models were almost ignored by the community until the 1990 s, when they were rediscovered [75], investigated in detail [76], and improved [77]. In this model, the kinetic behavior depends only on three factors: the initial hydroperoxide concentration $[\mathrm{POOH}]_{0}$, the initiation rate constant $k_{1}$, and a composite rate constant $r=\left(k_{3}^{2}[\mathrm{PH}]^{2}\right) / k_{6}$. This model starts from the hypothesis that oxygen is in excess, which allows to neglect termination processes IV and V (Table 5). However, there is no way, in this case, to simulate reaction-diffusion coupling. A solution elaborated in the 1980s [69-71] was available for this, but it was based on a set of questionable simplified assumptions, for instance, the constancy of initiation rate, or the existence of a relationship between termination rate constants $k_{5}^{2}=4 k_{4} \times k_{6}$.

Improvements were proposed in the frame of the study of polyimide-carbon composites [78]. At this time, the expression of oxygen consumption rate remains analytical. The following expressions give the steady concentrations of the main reactive species in the case of unimolecular initiation:

$$
\begin{aligned}
& {\left[\mathrm{P}^{\bullet}\right]=\frac{k_{3}[\mathrm{PH}]}{k_{5}} \frac{1}{1+\beta C},[\mathrm{POOH}]=\frac{k_{3}^{2}[\mathrm{PH}]^{2}}{k_{1} k_{6}} \frac{\beta C}{1+\beta C},} \\
& \text { and } \quad\left[\mathrm{PO}_{2}^{\bullet}\right]=\frac{k_{3}[\mathrm{PH}]}{k_{6}} \frac{\beta C}{1+\beta C},
\end{aligned}
$$

where $\beta=\left(k_{2} k_{6} / 2 k_{5} k_{3}[\mathrm{PH}]\right)$ and $C$ is the oxygen concentration.

The rate of oxygen consumption is given in steady state by:

$$
r_{\mathrm{ox}}=2\left(\frac{k_{3}^{2}[\mathrm{PH}]^{2}}{k_{6}}\right)\left(\frac{\beta C}{1+\beta C}\right)\left(1-\frac{\beta C}{2(1+\beta C)}\right)
$$

Possible experimental checks are carbonyl concentrations from Infrared (local) measurements, mass variations, and glass transition temperature $T_{\mathrm{g}}$ (local) measurements. These data can be connected to the kinetic model based on the following principle: propagation does not involve, in the cases under study, any secondary processes. The only physical consequence of propagation is a weight increase due to oxygen incorporation in reaction (II) (Table 5). All the other physical consequences of oxidation result essentially from fast secondary reactions accompanying hydroperoxide decomposition. Rearrangements of alkoxy radicals are important because they can generate volatile compounds and induce chain scission (Fig. 10).

The reactions accompanying unimolecular hydroperoxide decomposition and the corresponding balance equation are:

$$
\begin{array}{ll}
\mathrm{POOH} \longrightarrow & \mathrm{PO}^{\bullet}+{ }^{\bullet} \mathrm{OH} \\
\mathrm{HO}^{\bullet}+\mathrm{P} \longrightarrow & \mathrm{H}_{2} \mathrm{O}+\mathrm{P}^{\bullet} \\
\mathrm{PO}^{\bullet}+\mathrm{P} \longrightarrow & \mathrm{POH}+\mathrm{P}^{\bullet} \\
\mathrm{PO}^{\bullet} \longrightarrow & \mathrm{P}=\mathrm{O}+\mathrm{P}^{\bullet}+\mathrm{S}+\gamma_{\mathrm{V}} V \\
\hline \mathrm{POOH} \longrightarrow & 2 \mathrm{P}^{\bullet}+\mathrm{H}_{2} \mathrm{O}+\gamma_{1} \mathrm{P}=\mathrm{O}+\gamma_{\mathrm{S}} \mathrm{S} \\
& +\mathrm{v}_{1} V+\left(1-\gamma_{1}\right) \mathrm{POH} \quad \text { (balance equation) }
\end{array}
$$

\begin{tabular}{|c|c|c|c|c|}
\hline Initiation & Nonradical species $\rightarrow$ radicals & I & $\delta \mathrm{POOH} \rightarrow \alpha \mathrm{P}^{\bullet}+\beta \mathrm{PO}_{2}^{\bullet}$ & $\left(k_{1}\right)$ \\
\hline Propagation & One radical $\rightarrow$ one radical & II & $\mathrm{P}^{\bullet}+\mathrm{O}_{2} \rightarrow \mathrm{PO}_{2}^{\bullet}$ & $\left(k_{2}\right)$ \\
\hline Termination & Two radicals $\rightarrow$ nonradical species & III & $\begin{array}{l}\mathrm{PO}_{2}+\mathrm{PH} \rightarrow \mathrm{POOH}+\mathrm{P}^{-} \\
\mathrm{P}^{\bullet}+\mathrm{P}^{\bullet} \rightarrow \text { inactive products }\end{array}$ & $\left(k_{3}\right)$ \\
\hline Type of reaction & All radical chains & VI & $\begin{array}{c}\mathrm{PO}_{2} \\
\text { Thermal oxidation }\end{array}$ & $\left(k_{6}\right)$ \\
\hline
\end{tabular}

Table 5. Basic Radical Chain Mechanism Scheme and Standard Thermal Oxidation Mechanistic Scheme (For a Saturated Substrate) 


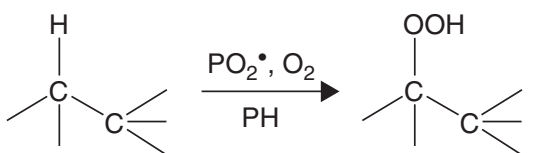<smiles>CC(C)([O])C1CC1</smiles>

where $V$ is a hypothetical volatile molecule, the molar mass of which would be the number average of volatile molar masses; $\gamma_{V}$ is the yield of volatile formation in the $\mathrm{PO}^{\bullet}$ rearrangement; $\gamma_{1}$ is the yield of $\mathrm{PO}^{\bullet}$ rearrangement among $\mathrm{PO}^{\circ}$ reactions; and $\mathrm{V}=\gamma_{1} \times \gamma_{\mathrm{V}}$ is the yield of volatiles per initiation event.

Water is formed only in $\mathrm{POOH}$ decomposition.

$\mathrm{PO}$ • radicals can also result from bimolecular peroxyl combinations, so that, in the general case, it can be written:

$$
\begin{gathered}
\frac{\mathrm{d}\left[\mathrm{H}_{2} \mathrm{O}\right]}{\mathrm{d} t}=k_{1}[\mathrm{POOH}], \frac{\mathrm{d}[\mathrm{P=O}]}{\mathrm{d} t}=\gamma_{1} k_{1}[\mathrm{POOH}]+\gamma_{6} k_{6}\left[\mathrm{PO}_{2}^{*}\right]^{2} \\
\frac{\mathrm{d} v}{\mathrm{~d} t}=v_{1} k_{1}[\mathrm{POOH}]+v_{6} k_{6}\left[\mathrm{PO}_{2}^{*}\right]^{2}, \text { and so on }
\end{gathered}
$$

In general, however, the kinetics is not far from the steady state, which means that initiation and termination rates are close. In these cases, one can suppress the termination term $\left(k_{6}\left[\mathrm{PO}_{2}{ }^{\circ}\right]^{2}\right)$ in the above equations and modify the coefficient $\gamma_{1}$ to take into account both the initiation and termination rates.

The mass variation is thus the algebraic sum of two members:

$$
\frac{\mathrm{d} m}{\mathrm{~d} t}=\frac{1}{\rho}\left\{32 k_{2} C\left[\mathrm{P}^{\bullet}\right]-\left(18+v_{1} M_{\mathrm{V}}\right) k_{1}[\mathrm{POOH}\}\right.
$$

The first term $\left(32 k_{2} C\left[\mathrm{P}^{\bullet}\right]\right)$ is linked to the propagation rate, whereas the second term $\left(\left(18+v_{1} M_{V}\right) k_{1}[\mathrm{POOH}]\right)$ is linked to the initiation rate. A peculiarity of the hydroperoxide-initiated oxidation is that the kinetic chain length (the propagation rate/initiation rate ratio) decreases continuously during the initial period of exposure to tend asymptotically toward unity. One can thus find cases where, in an initial period, $32 k_{2} C\left[\mathrm{P}^{\circ}\right]>\left(18+v_{1} M_{V}\right) k_{1}[\mathrm{POOH}]$ so that the mass increases, whereas, at long term, the inequality is inversed and the mass decreases. Poly(bismaleimides) display this nonmonotonous behavior, whereas epoxy networks, in which hydroperoxides are highly unstable, loose mass continuously. The ability of the model to simulate these variety of behaviors [79] can be considered as a positive argument in its favor.

\section{Structure-Stability Relationships}

The polymer oxidizability depends on many factors, and the most important ones are listed in Table 6.

Concerning first chemical factors, it is clear that propagation by hydrogen abstraction $\left(k_{3}\right)$ plays a key role. Structure $-k_{3}$ relationships are relatively well known [80]. Taking polyethylene (methylene in a polymethylenic sequence) as a reference, one can distinguish two families:

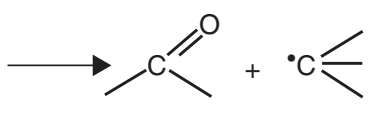

Figure 10. Sequence of reactions leading to chain scission by alkoxy radical rearrangement ( $\beta$ scission)

Table 6. Main Factors Influencing Polymer Oxidizability

\begin{tabular}{lc}
\hline Factors & Effect on Oxidation Rate \\
\hline Substrate concentration $([\mathrm{PH}])$ & + \\
Initiation rate constant $\left(k_{1}\right)$ & - \\
Propagation rate constant $\left(k_{3}\right)$ & ++ \\
Termination rate constant $\left(k_{6}\right)$ & + \\
Composite rate constant & ++ \\
{$\left[\left(\mathrm{k}_{3}{ }^{2}[\mathrm{PH}]^{2}\right) / \mathrm{k}_{6}\right]$} & \\
Oxygen solubility $(S)$ & + \\
Oxygen diffusivity $(D)$ & + \\
Presence of antioxidants & - \\
\hline
\end{tabular}

- More stable polymers: Those containing no $\mathrm{CH}$ bonds (e.g., PTFE) or containing only

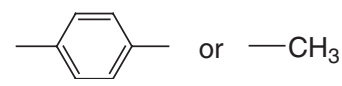

- Less stable polymers: Those containing<smiles>CC(=CC(C)OC(C)C(C)C(C)C)C(C)C</smiles>

Polyetheretherketone (PEEK), poly(ether sulfones), polypyromellitimide, poly(dimethyl siloxane), poly (bisphenol sulfones), poly(bisphenol A carbonate), and so on belong to the first category. Polypropylene, polydienes, polyesters, polyamides, amine-cross-linked epoxies, and so on belong to the second category.

Indeed, oxygen transport properties are very important. If its permeability is very low (polymer glasses), oxidation will be restricted to a very thin superficial layer and will not have mechanical consequences.

The initial fracture behavior is also important. In initially ductile polymers, a very small number of chain scissions are able to induce a deep embrittlement. In contrast, in initially brittle polymers, a big number of chain scission events are needed to have significant consequences on the fracture behavior.

\section{Kinetic Control by Oxygen Diffusion. New Developments}

The classical approach of the reaction-diffusion coupling involves two steps:

1. The determination of the function linking the oxygen consumption rate to the oxygen concentration $r(C)$.

2. The resolution of Equation (9):

$$
\frac{\partial C}{\partial t}=D\left(\frac{\partial^{2} C}{\partial z^{2}}\right)-r(C)
$$


As previously quoted in the section titled "ReactionDiffusion Coupling," a new approach was proposed in the beginning of 2000 s (e.g., [29]). It was to integrate diffusion-reaction coupling in the set of differential equations constituting the kinetic scheme. Oxygen is always involved in two elementary steps, and it is consumed in step II (Table 5):

$$
\mathrm{P}^{\bullet}+\mathrm{O}_{2} \rightarrow \mathrm{PO}_{2}^{\bullet}
$$

and restituted in step VI:

$$
\mathrm{PO}_{2}{ }^{\bullet}+\mathrm{PO}_{2}{ }^{\bullet} \rightarrow \text { inactive products }+\mathrm{O}_{2}
$$

Thus, in all cases:

$$
\frac{\partial C}{\partial t}=D\left(\frac{\partial^{2} C}{\partial z^{2}}\right)-k_{2} C\left[\mathrm{P}^{\bullet}\right]+k_{6}\left[\mathrm{PO}_{2}^{\bullet}\right]^{2}
$$

Many authors, in the past, have neglected the termination term $\left(k_{6}\left[\mathrm{PO}_{2}{ }^{\circ}\right]^{2}\right)$, but, since the kinetic chain length tends toward unity, this can carry noticeable errors.

The predictive value of this approach is clearly attested by experimental determinations of oxidation profiles $[81,82]$. Recent developments take into account fast diffusion in the interfacial region, role of cracks, and so on [83]. For these last authors, thermo-oxidation remains diffusion controlled as long as the material keeps its integrity. When cracks appear, they become the preferential way for oxygen penetration into deep layers. Homogenization approaches then allow to determine an effective oxygen diffusivity, including all the above-mentioned factors (interphase, cracks, etc.) [21].

\section{Consequences of Oxidation}

Shrinkage. Oxidation leads practically always to density increase and volatile evolution. Density increase results from the replacement of light atoms $(\mathrm{C}, \mathrm{H})$ by heavy ones $(\mathrm{O})$. For a constitutive repeat unit, an "average atomic mass" $M_{\mathrm{A}}$ can be defined as:

$$
\mathrm{M}_{A}=\frac{\text { Molar mass }}{\text { Number of atoms }} .
$$

$M_{\mathrm{A}}$ can be derived from the kinetic scheme, making simple assumptions about the nature of oxidation products [27]. The density can be calculated from an empirical relationship [84]:

$$
\rho=350+120 M_{\mathrm{A}},
$$

where $\rho$ is expressed in kilograms per cubic millimeters and $M_{\mathrm{A}}$ in grams per moles.

The relative volume change is then given by:

$$
\frac{\Delta v}{v}=\frac{\Delta m}{m}-\frac{\Delta \rho}{\rho} \text {. }
$$

$\Delta \rho / \rho$ is always positive. $\Delta m / m$ can be positive in the early period of exposure, but becomes negative at long term. Thus, oxidation generates shrinkage that induces a stress state, which, in turn, can induce damage, for instance, matrix-fiber debonding [85].
Change of Glass Transition Temperature $T_{\mathrm{g}}$. In scarce cases of unsaturated matrices, for instance, epoxies cured by MTHPA (methyltetrahydrophthalic anhydride), radical addition to double bonds induces predominant cross-linking [86]. In most cases, however, chain scission predominates largely over cross-linking owing to the importance of $\mathrm{PO}^{\bullet} \beta$ scissions (The Standard Mechanistic Scheme).

Cross-linking and chain scission events can be associated to an elementary step of the mechanistic scheme, so that their respective numbers $X$ and $S$ can be calculated by the kinetic model. In linear polymers, the number $\left(M_{\mathrm{n}}\right)$ and weight $\left(M_{\mathrm{W}}\right)$ of the average molar masses are linked to $S$ and $X$ by the following equations [87]:

$$
\begin{gathered}
\frac{1}{M_{\mathrm{n}}}-\frac{1}{M_{\mathrm{n} 0}}=S-X, \\
\frac{1}{M_{\mathrm{W}}}-\frac{1}{M_{\mathrm{W} 0}}=\frac{S}{2}-2 X .
\end{gathered}
$$

When the chain scission predominates $(S>4 X)$, both molar masses decrease, and the glass transition temperature decreases. According to the Fox-Flory law [88], if cross-linking is negligible:

$$
T_{\mathrm{g}}=T_{\mathrm{g} \infty}-\frac{K_{\mathrm{FF}}}{M_{\mathrm{n}}}
$$

so that

$$
T_{\mathrm{g} 0}-T_{\mathrm{g}}=K_{\mathrm{FF}} S,
$$

where $T_{g 0}$ and $T_{\mathrm{g}}$ are the respective glass transition temperatures before and after degradation and $T_{\mathrm{g} \infty}$ and $K_{\mathrm{FF}}$ are material constants. According to Bicerano [89]:

$$
K_{\mathrm{FF}}=2.715 \times 10^{-3} T_{\mathrm{g} \infty}^{3} .
$$

When cross-linking largely predominates, gelation occurs at:

$$
X=\frac{1}{2 M_{\mathrm{W} 0}} .
$$

$T_{\mathrm{g}}$ increases with $X$, but the slope $\mathrm{d} T_{\mathrm{g}} / \mathrm{d} X$ is considerably lower than the absolute value of $\mathrm{d} T_{\mathrm{g}} / \mathrm{d} S$.

The relationship between the cross-linking density, the number of chain scissions, and/or cross-linking events can be relatively complex in nonideal networks (e.g., networks with dangling chains). In almost ideal networks, in the case of a predominating chain scission, one can write [84]:

$$
v=v_{0}-\psi S,
$$

where $v_{0}$ and $v$ are the concentrations of elastically active chains before and after aging, respectively. $\psi=3$ for networks with trifunctional cross-links (amine-cross-linked epoxies), and $\psi=1$ for all the other networks.

When cross-linking largely predominates:

$$
v=v_{0}+2 X, \quad \text { in all the networks. }
$$


$T_{\mathrm{g}}$ is an increasing function of $v$. There are many relationships in the literature, the better one being, to our opinion [90], Di Marzio's equation [91]:

$$
T_{\mathrm{g}}=\frac{T_{\mathrm{gl}}}{1-2 F \nu} .
$$

$T_{\mathrm{gl}}$ and $F$ being characteristics of the network chains (essentially their dynamic stiffness). Thus, here also, chain scission leads to a decrease in $T_{\mathrm{g}}$, and cross-linking leads to an increase in $T_{\mathrm{g}}$. One can remark that:

$$
\frac{T_{\mathrm{g}}}{\mathrm{d} v}=2 \frac{F T_{\mathrm{g}}^{2}}{T_{\mathrm{gl}}} .
$$

In other words, the sensitivity of $T_{\mathrm{g}}$ to a change in cross-link density is an increasing function of $T_{\mathrm{g}}$.

Change of Elastic Properties. Elastic properties depend essentially on two factors: the cohesive energy density and the local mobility (responsible for subglass transitions at temperatures lower than the temperature at which elastic properties are measured). It can be written, schematically, in glassy state:

$$
\begin{gathered}
K=K_{0}\left(1-\alpha_{\mathrm{K}} \frac{T}{T_{\mathrm{g}}}\right) \quad \text { (bulk modulus), } \\
E=E_{0}\left(1-\alpha_{\mathrm{E}} \frac{T}{T_{\mathrm{g}}}\right)-\sum_{i} \Delta E_{\mathrm{i}} \quad \text { (Young's modulus), } \\
G=G_{0}\left(1-\alpha_{\mathrm{G}} \frac{T}{T_{\mathrm{g}}}\right)-\sum_{i} \Delta G_{\mathrm{i}} \quad \text { (shear modulus), } \\
\mu=0.5-\alpha_{\mu}\left(1-\frac{T}{T_{\mathrm{g}}}\right)+\sum_{i} \Delta \mu_{\mathrm{i}} \quad \text { (Poisson's ratio), }
\end{gathered}
$$

where $\alpha_{\mathrm{K}}, \alpha_{\mathrm{E}}, \alpha_{\mathrm{G}}$, and $\alpha_{\mu}$ are coefficients of the order of $0.3-0.5 . \Delta E_{\mathrm{i}}, \Delta G_{\mathrm{i}}$, and $\Delta \mu_{i}$ are the respective gaps of Young's modulus, the shear modulus, and Poisson's ratio at the $i$ th secondary transition below the measurement temperature $T$.

The bulk modulus is not affected by the secondary transitions. $K_{0}, E_{0}, G_{0}$, and $\mu_{0}$ depend only on the cohesive energy density. $\Delta E_{\mathrm{i}}, \Delta G_{\mathrm{i}}$, and $\Delta \mu_{\mathrm{i}}$ are interrelated and depend on the activity of secondary transitions.

In linear polymers, it seems that a deep embrittlement occurs far before these properties have significantly changed. In certain networks displaying weak secondary transitions, such as styrene-cross-linked polyesters or vinyl esters, no significant changes of elastic properties (in a reasonable range of conversions) are expected. In networks displaying secondary transitions of noticeable activity, such as amine-cross-linked epoxies, the changes resulting from chain scissions are illustrated by Fig. 11.

In these networks, chain scission induces a decrease in the activity of $\beta$ transition and thus an increase in the shear or Young's modulus and the concomitant decrease of Poisson's ratio, with the bulk modulus being

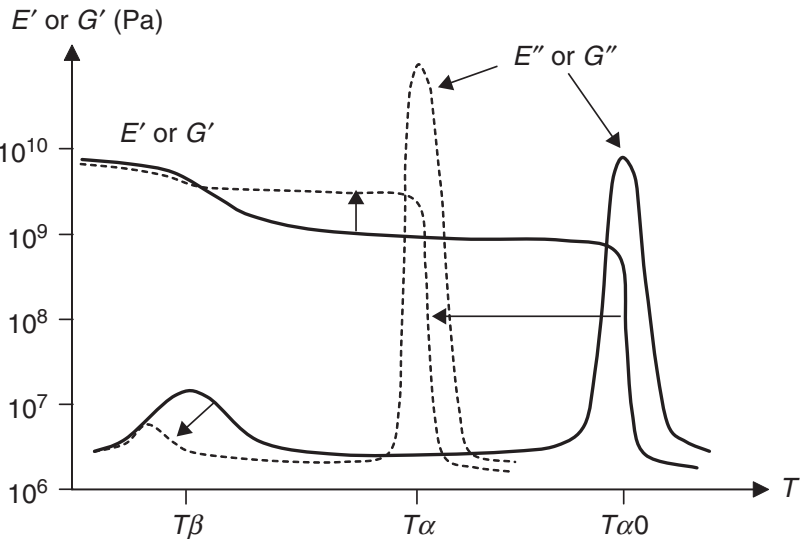

Figure 11. Shape of dynamic mechanical analysis (DMA) curves for a network before (full line) and after degradation (dashed line). The horizontal arrow indicates the decrease of $T_{\mathrm{g}}$ resulting from a predominating chain scission. The vertical arrow indicates the increase of modulus on the glassy plateau above $T_{\beta}$. The oblique arrow indicates the change in amplitude and temperature of the $\beta$ transition.

not affected. Rasoldier et al. [92] have shown that, in the case of amine-cross-linked epoxies, this "antiplasticization" phenomenon is also displayed in virgin networks having an epoxide excess. These networks can thus be used as model networks. In polymerization of monomer reactants (PMR-15), the modulus increases also in the oxidized layer based, presumably, on the same mechanism [93].

There is no physical theory, to our knowledge, to establish a relationship between the network structure and elastic properties. This step of the lifetime prediction approach will remain empirical for a certain time.

Change in Fracture Properties. The trends described in the case of hydrolysis (see the section titled "Consequences of Hydrolysis") remain valid here. In the case of networks, it is observed that both cross-linking and chain scission lead to embrittlement for distinct reasons: cross-linking presumably shifts ductile-brittle transition toward high temperatures, and chain scission reduces the number of covalent bonds per volume unit, which presumably affects the brittle fracture behavior. These research domains are far from being systematically explored and would need noticeable research efforts.

An example of changes in fracture properties during thermal aging is reported in Fig. 12. Anhydride-cured epoxy matrix and its corresponding composites filled with $60 \mathrm{wt} \%$ of silica or $50 \mathrm{wt} \%$ of trihydrated alumina were exposed to air at various temperatures ranging from 140 to $200^{\circ} \mathrm{C}$, and their fracture properties were determined in flexural mode. The curves are rupture envelopes, that is, stress at break $\sigma_{R}$ against ultimate deflection $\varepsilon_{R}$. In three cases, they coincide with initial stress-deflection curves. Here, oxidative aging does not modify the sample's mechanical behavior but creates superficial defects making the rupture occur sooner and sooner [94].

$N B$ : The matrix is initially semiductile, and the maximum on the curves corresponds to the yield. 


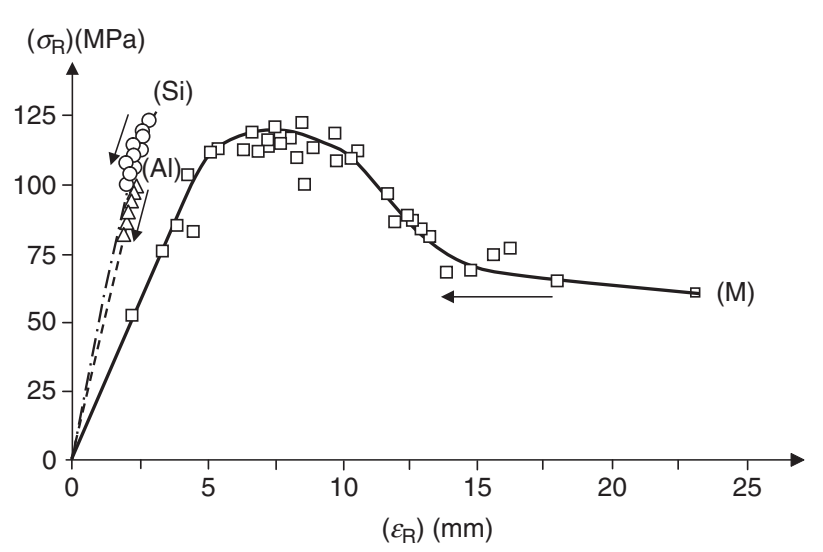

Figure 12. Rupture envelopes for an anhydride-cured epoxy matrix $(\square, M)$ and its corresponding composites filled with $60 \mathrm{wt} \%$ of silica $(O, \mathrm{Si})$ or $50 \mathrm{wt} \%$ of trihydrated alumina $(\Delta, \mathrm{Al})$ after thermal aging in air at various temperatures ranging from 140 to $200^{\circ} \mathrm{C}$. Fracture properties were determined in flexural mode. The arrows indicate the sense of aging effect. Source: Ref. 94.

\section{CONCLUSIONS}

In common use conditions, OMCs perish mainly because of humid or thermal oxidative aging.

Humid aging can be physical or chemical. Physical aging results mainly from damage induced by swelling stresses. There are now sophisticated tools for the mechanical analysis of this process, but some questions, for instance, relative to the effect of structure on water diffusivity and swelling ratio, remain largely open. Swelling mechanisms are, to our opinion, far from being fully understood. Chemical aging results from hydrolysis that includes osmotic cracking, especially in unsaturated polyester composites. Here, mechanisms and kinetics are almost fully elucidated in the case of matrix hydrolysis. However, interface/interphase can play a key role. We dispose of a great number of experimental observations in this field, but they are difficult to translate into nonempirical degradation kinetics laws. This domain will need noticeable research efforts in the future to reach the level required by kinetic modeling and lifetime prediction.

The thermal oxidative aging domain suffered a long stagnation period, partially because of the lack of communication between the polymer and composite communities. Joining these communities and introduction of numerical methods in the resolution of kinetic schemes recently created a strong impulse. Models having good predictive properties are now available, but they can still be considerably improved, especially in the following directions: (i) measurement of oxygen transport properties in composites, (ii) relationships between chemical changes and use properties (especially fracture properties), and (iii) role of interface/interphase.

In both humid and thermal oxidative aging domains, stress effects on diffusion and chemical reaction, which have been almost totally ignored in the past, will need also to be systematically investigated.

In the future, the turn of the century will probably appear as a transition period during which empiricism has been progressively eradicated and replaced fully by scientific approach of lifetime prediction for OMCs.

\section{REFERENCES}

1. Schapery RA. Further developments of a thermodynamic constitutive theory: stress formulation. Report No. AA \& ES 69-2. Purdue University. West Lafayette; 1969.

2. Talreja R. Damage mechanics of composite materials based on thermodynamics with internal variables. In: Cardon $\mathrm{AH}$ Verchery G, editors. Proceedings of International Symposium on Durability Analysis of Polymer Based Composite Systems for Structural Applications. New York: Elsevier Applied Science; 1991. pp. 65-79.

3. Cardon AH. Recent advances in durability analysis of polymer based composites. In: Di Benedetto AT, Nicolais LN, Watanabe H, editors. Composite materials. New York: Elsevier; 1992. pp. 23-38.

4. Reifsnider KL. Performance simulation of polymer based composite systems. In: Cardon AH, Verchery G, editors. Proceedings of International Symposium on Durability Analysis of Polymer Based Composite Systems for Structural Applications. New York: Elsevier Applied Science; 1991. pp. 3-26.

5. Bellenger V, Verdu J. J Appl Polym Sci 1983;28(88): 2599-2609 and 28(99):2677-2688.

6. Wilski H, O'Donnell JH. Influence of ionizing radiation on thermoset plastics. In: Clough RL, Shalaby SW, editors. Radiation effects on polymers, ACS Symposium Series 475. Washington (DC): American Chemical Society; 1991. pp. 402-413.

7. Van de Voorde MH, Restat C. Selection guide to organic materials in nuclear engineering. Report No. CERN 72-7. Geneva, Switzerland; 1972.

8. Struik LCE. Physical aging in amorphous polymers and other materials. Amsterdam: Elsevier; 1978.

9. Kong ES, Wilkes GL, McGrath JE, Banthia AK, Mohajer Y, Tant MR. Polym Eng Sci 1981;21(14):943-950.

10. Theberge JE. Volume 2-D, Proceedings of the 25th Annual Technical Conference of Reinforced Plastics/Composites Division. Washington (DC): The Society of Plastics Industry; 1970. pp. 1.

11. Ishida H. Polym Compos 1984;5(2):101-123.

12. Ishida H. Structural gradient in the silane coupling agent layers and its influence on the mechanical and physical properties of composites. In: Ishida H, Kumar G, editors. Molecular characterization of composite interfaces. New York: Plenum Press; 1985. pp. 25-50.

13. Thomason JL. Polym Compos 1990;11(2):105-113.

14. Pitkethly MJ, Favre J-P, Gaur U, Jakubowski J, Mudrich SF, Caldwell DL, Drzal LT, Nardin M, Wagner HD, Di Landro L, Hampe A, Armistead JP, Desaeger M, Verposet I. Compos Sci Technol 1993;48:205-214.

15. Barrer RM. Diffusion and permeation in heterogeneous media. In: Crank J, Park GS, editors. Diffusion in polymers. 4th ed. London: Academic Press; 1968. pp. 165-217, Chapter 6.

16. Barjasteh E, Bosze EJ, Tsai YI, Nutt SR. Compos Part A Appl Sci Manuf 2009;40:2038-2045.

17. Ziegel KD, Frensdorff HK, Blair DE. J Polym Sci Part A-2: Polym Phys 1969;7:809-819.

18. Tsai SW. Composite design. 4th ed. Dayton (OH): Think composites; 1988.

19. Kondo K, Taki T. J Compos Mater 1982;16(2):82-93. 
20. Colin X, Mavel A, Marais C, Verdu J. J Compos Mater 2005a;39(15):1371-1389.

21. Roy S, Singh S. Compos Sci Technol 2009;69(11-12): 1962-1967.

22. Kumins KA, Kwei TK. Free volume and other theories. In: Crank J, Park GS, editors. Diffusion in Polymers. London: Academic Press Inc.; 1968. pp. 105-140, Chapter 4.

23. Di Benedetto AT, Paul DR. J Polym Sci Part A Polym Chem 1964;2:1001-1015.

24. Tcharkhtchi A, Bronnec Y, Verdu J. Polymer 2000;41(15): 5777-5785.

25. Derrien K, Gilormini P. Interaction between stress and diffusion in polymers. Proceedings of the DSL 2006 Conference, Defect and Diffusion Forum 258/260. Lisbon, Portugal; 2006. pp. 447-452.

26. Rambert G, Jugla G, Grandidier J-C, Cangemi L. Compos Part A Appl Sci Manuf 2006;37(4):571-584

27. Colin X, Verdu J. Compos Sci Technol 2005b;65:411-419.

28. Audouin L, Langlois V, Verdu J, De Bruijn JCM. J Mater Sci 1994;29:569-583.

29. Rincon-Rubio LM, Colin X, Audouin L, Verdu J. Rubber Chem Technol 2003;76(2):460-482.

30. Olivier L. Prediction of thermal oxidative aging of organic matrix composites dedicated to aeronautics. [ $\mathrm{PhD}$ thesis. University of Poitiers, France; 2008. Oct.

31. Jacquemet R. Study of aging behaviour under mechanical loading of $\mathrm{E}$ glass/polyester laminates in a marine medium. $[\mathrm{PhD}$ thesis]. University of Nancy, France. 2008. June.

32. Gaudichet-Maurin E. Characterization and aging of a water ultrafiltration membrane. $[\mathrm{PhD}$ thesis]. ENSAM, Paris. 2005. Oct.

33. Coquillat M, Audouin L, Verdu J. Interaction of aliphatic polyesters with water; 2012. to be published.

34. Zimm BH, Lundberg JL. J Phys Chem 1956;60:425-428.

35. Barrie JA. Water in polymers. In: Crank J, Park GS, editors. Diffusion in polymers. 4th ed. London: Academic Press; 1968. pp. 259-313, Chapter 8.

36. Marque G, Neyertz S, Verdu J, Prunier V, Brown D. Macromolecules 2008;41(9):3349-3362.

37. Merdas I, Thominette F, Tcharkhtchi A, Verdu J. Compos Sci Technol 2002;62:487-492.

38. Johncock P, Tudgey GF. Br Polym J 1986;18(5):292-302.

39. van Krevelen DW. Properties of polymers: their estimation and correlation with chemical structure. 3rd ed. Amsterdam: Elsevier; 1990. pp. 571-573, Chapter 18.

40. Bellenger V, Verdu J, Morel E. J Mater Sci 1989;24(1):63-68.

41. Gaudichet-Maurin E, Thominette F, Verdu J. J Appl Polym Sci 2008;109:3279-3285.

42. Kelley N, Bueche FJ. J Polym Sci 1961;50:549-556.

43. Belan F, Bellenger V, Mortaigne B, Verdu J. Polym Degrad Stab 1997;56:301-309.

44. Marque G. Water absorption in polymers. [PhD thesis. University of Chambery; 2009. April (and an article to be published).

45. Carter HG, Kibler KG. J Compos Mater 1978;12:118-131.

46. Apicella A, Nicolais L. Adv Polym Sci 1985;72:70-77.

47. Thominette F, Gaudichet-Maurin E, Verdu J. Effect of structure on water diffusion in moderately hydrophilic polymers. Proceedings of the DSL 2006 Conference, Defect and Diffusion Forum 258/260. Lisbon, Portugal; 2008. pp. 442-446.
48. Gurtin ME. On the linear theory of diffusion through an elastic solid. In: Louthran MR Jr, McNitt RP, editors. Proceedings of the Conference on Environmental Degradation of Engineering Materials. Blacksburg (VA): Virginia Tech; 1977. pp. 151-160.

49. Weitsman Y. J Mech Phys Solids 1987;35(1):73-93

50. Wu C. J Mech Phys Solids 2001;49:1771-1794.

51. Bellenger V, Ganem M, Mortaigne B, Verdu J. Polym Degrad Stab 1995;49(1):91-97.

52. Jacques B, Werth M, Merdas I, Thominette F, Verdu J. Polymer 2002;43:6439-6447.

53. Merdas I, Thominette F, Verdu J. Polym Degrad Stab 2003; 79:419-425.

54. Ishida H, Koenig JL. J Polym Sci Part B Polym Phys 1980; 18:1931-1943.

55. Hoh K-P, Ishida H, Koenig JL. Polym Compos 1990;11(3): 192-199.

56. Salmon L, Thominette F, Pays M-F, Verdu J. Compos Sci Technol 1997;57:1119-1127.

57. Fayolle B, Richaud E, Colin X, Verdu J. J Mater Sci 2008; 43:6999-7012.

58. Ashbee KHG, Frank FC, Wyatt RC. Proc R Soc Lond 1967; A300:415-419.

59. Ashbee KHG, Wyatt RC. Proc R Soc Lond 1969;A312: 553-564.

60. Gautier L, Mortaigne B, Bellenger V, Verdu J. Polymer 1999; 41(7):2481-2490.

61. Mortaigne B, Bellenger V, Verdu J. Polym Netw Blends 1992;2(4):187-195.

62. Semenov NN. Chemical kinetics and chain reactions. London: Oxford University Press; 1935

63. Bolland JL, Gee G. Trans Faraday Soc 1946;42:236-243 and 244-252.

64. Tobolsky AV, Metz DJ, Mesrobian RB. J Am Chem Soc 1950;72:1942-1952.

65. Lundberg WO. Volumes 1 and 2, Autoxidation and antioxidants. New York: Interscience; 1961

66. Reich L, Stivala S. Autoxidation of hydrocarbons and polyolefins: kinetics and mechanisms. New York: Marcel Dekker; 1969.

67. Emanuel NM, Denisov ET, Marzus ZK. Liquid phase oxidation of hydrocarbons. New York: Plenum Press; 1967.

68. Emanuel NM, Buchachenko AL. Chemical physics of polymer degradation and stabilization. Ultrech, The Netherlands: VNU Science Press; 1987

69. Furneaux GC, Ledbury KJ, Davis A. Polym Degrad Stab 1981;3(6):431-442.

70. Cunliffe AV, Davis A. Polym Degrad Stab 1982;4(1):17-37.

71. Seguchi T, Hashimoto S, Arakawa K, Hayakawa N, Kawakami W, Kuriyama I. Radiat Phys Chem 1981;17(4): 195-201.

72. Nam JD, Seferis JC. SAMPE Q 1992;24(1):10-18.

73. Salin JM, Seferis JC. J Polym Sci Part B Polym Phys 1993;31:1019-1027.

74. Cunningham RA, McManus HL. Coupled diffusion-reaction models for predicting the distribution of degradation in polymer matrix composites. Proceedings of the ASME Aerospace Division, Volume 52. New York; 1996. p. 353.

75. Audouin L, Gueguen V, Tcharkhtchi A, Verdu J. J Polym Sci Part A Polym Chem 1995;33(6):921-927. 
76. Audouin L, Achimsky L, Verdu J. Modelling of hydrocarbon polymer oxidation. In: Halim Hamid S, editor. Handbook of polymer degradation. 2nd ed. New York: Marcel Dekker; 2000. pp. 727-763, Chapter 20.

77. Colin X, Fayolle B, Audouin L, Verdu J. Int J Chem Kinet 2006;38(11):666-676.

78. Colin X, Marais C, Verdu J. J Appl Polym Sci 2001a;82(14): 3418-3430.

79. Colin X, Marais C, Verdu J. Polym Degrad Stab 2002;78(3): $545-553$

80. Korcek S, Chenier JHB, Howard JA, Ingold KU. Can J Chem 1972;50:2285-2297.

81. Colin X, Marais C, Verdu J. Polym Test 2001b;20(7): $795-803$

82. Olivier L, Ho NQ, Grandidier J-C, Lafarie-Frenot M-C. Polym Degrad Stab 2008;93:489-497.

83. Pochiraju KV, Tandon GP, Schoeppner GA. Mech TimeDependent Mater 2008;12(1):45-68.

84. Pascault J-P, Sautereau H, Verdu J, Williams RJJ. Thermosetting polymers. New York: Marcel Dekker; 2002. pp. 284. Chapter 10.
85. Rouquier S, Lafarie-Frenot M-C, Cinquin J, Colombaro AM. Compos Sci Technol 2005;65(3-4):403-409.

86. Le Huy HM, Bellenger V, Paris M, Verdu J. Polym Degrad Stab 1992;35:77-86.

87. Saito O. J Phys Soc Jpn 1958;13(2):198-206 and 1958;13(12): 1451-1464.

88. Fox TG, Flory PJ. J Appl Phys 1950;21:581-591.

89. Bicerano J. Prediction of polymer properties. 3rd ed. New York: Marcel Dekker; 2002.

90. Bellenger V, Morel E, Verdu J. J Polym Sci Part B Polym Phys 1987;25(6):1219-1234.

91. Di Marzio EA. J Res Natl Bur Stand A Phys Chem 1964;68:611-617.

92. Rasoldier N, Colin X, Verdu J, Bocquet M, Olivier L, Chocinski-Arnault L, Lafarie-Frenot M-C. Compos Part A Appl Sci Manuf 2008;39:1522-1529.

93. Tandon GP, Pochiraju KV, Schoeppner GA. Polym Degrad Stab 2006;91:1861-1869.

94. Le Huy HM, Bellenger V, Verdu J, Paris M. Polym Degrad Stab 1993;41:149-156. 